Canadian

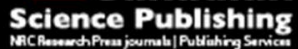

Canadian Journal of Physiology and Pharmacology Revue canadienne de physiologie et pharmacologie

\title{
Renoprotective Effects Aliskiren on Adenine-induced Tubulointerstitial Nephropathy: Possible Underlying Mechanisms
}

\begin{tabular}{|r|l|}
\hline Journal: & Canadian Journal of Physiology and Pharmacology \\
\hline Manuscript ID & cjpp-2015-0364.R1 \\
\hline Manuscript Type: & Article \\
\hline Date Submitted by the Author: & 07-Dec-2015 \\
\hline Complete List of Authors: & $\begin{array}{l}\text { Hussein, Abdelaziz; Mansoura,Faculty of Medicine, Medical Physiology } \\
\text { Malek, Hala; Mansoura University, Clinical Pharmacology Dept } \\
\text { Saad, Mohamed-Ahdy; Mansoura University, Clinical Pharmacology Dept. }\end{array}$ \\
\hline Keyword: & adenine, nephropathy, nrf2, caspase-3, eNOS, oxidative stress \\
\hline
\end{tabular}

SCHOLARONE ${ }^{m}$

Manuscripts 


\title{
Renoprotective Effects Aliskiren on Adenine-induced Tubulointerstitial Nephropathy: Possible Underlying Mechanisms
}

\author{
Abdelaziz M. Hussein ${ }^{\dagger}$, Hala Abdel Malek ${ }^{\$}$ and Mohamed Ahdy Saad ${ }^{\$}$ \\ ${ }^{\dagger}$ Medical Physiology Department, Faculty of Medicine, Mansoura University, Mansoura, Egypt \\ ${ }^{\$}$ Clinical Pharmacology Department, Faculty of Medicine, Mansoura University, Mansoura, \\ Egypt
}

\section{Corresponding author}

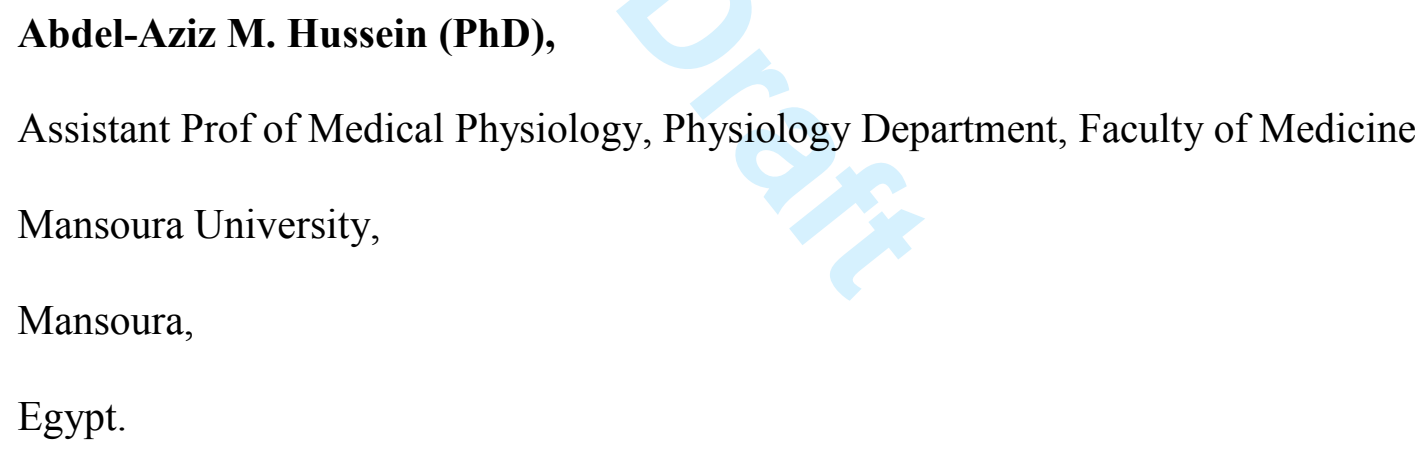

PO: 35516

Short title: Aliskiren and adenine induced nephropathy 


\begin{abstract}
The present study investigated the possible renoprotective effect of direct renin inhibitor (aliskiren) on renal dysfunctions as well as its underlying mechanisms in rat model of adenine -induced tubulointerstitial nephropathy. Forty male Sprague Dawley rats were randomized into 4 groups; normal group, aliskiren group (normal rats received $10 \mathrm{mg} / \mathrm{kg}$ aliskiren), adenine group (animals received high adenine diet for 4 weeks and saline for 12 weeks) and aliskiren group (animals received adenine for 4 weeks and aliskiren 10 $\mathrm{mg} / \mathrm{kg}$ for 12 weeks). It was found that adenine caused significant decrease in body weight, $\mathrm{Hb}, \mathrm{HR}$, serum $\mathrm{Ca}^{+2}$, eNOS and nrf2 expression, GSH and catalase in kidney tissues with significant increase in arterial blood pressure (ABP), serum creatinine, BUN, plasma renin activity (PRA), $\mathrm{K}^{+}$and $\mathrm{P}$, urinary albumin excretion (UAE), caspase-3 and MDA (lipid peroxidation marker) in kidney tissues compared to normal group $(p<0.05)$. Administration of aliskiren caused significant improvement in all studied parameters compared to adenine group $(p<0.05)$. We concluded that aliskiren has renoprotective effect against adenine-induced nephropathy. This might be due to inhibition of PRA, attenuation of oxidative stress, activation of Nrf2 and eNOS genes and suppression of caspase-3.
\end{abstract}

Key words: adenine, nephropathy, nrf2, caspase-3, eNOS, oxidative stress 


\section{Introduction}

Nowadays, chronic kidney disease (CKD) is a world-wide health problem and one of the leading causes of death (Levey et al. 2007). Over the past decades, there is an alarming increase in prevalence of CKD and end-stage renal disease which is promoted by growing the prevalence of cardiovascular risk factors such as obesity, diabetes, and hypertension that increase the overall morbidity and mortality in these patients. Therefore, it is mandatory to identify its underlying mechanisms which aggravate renal dysfunction and scarring and to develop new therapeutic strategies that prevent and attenuate CKD (Lerman and Chade 2009). Adenine-induced nephropathy exhibits severe tubulo-interstitial nephropathy (TIN) which causes CKD resembling that seen in humans (Ataka et al. 2003; Lavi-Moshayoff et al. 2010; Matsui et al. 2009; Tamagaki et al. 2006; Yokozawa et al. 1986). The underling pathophysiological mechanisms of adenineinduced nephropathy involves precipitation of dihydroxyadenine in renal tubules causing tubular cell injury and apoptosis, interstitial inflammatory cell infiltration and tubulointerstitial fibrosis resulting in progressive deterioration of kidney functions and CKD (Tamura et al. 2009; Tanaka et al. 2009). Recently, Aminzadeh et al. (2013) demonstrated enhanced oxidative stress and inflammatory reaction in the kidneys of adenine-treated animals which was accompanied by an impaired activation of nrf2 gene with down-regulation of its dependent-genes products such as heme oxygenase-1 (HO-1), glutamate-cysteine ligase and catalase.

Renin angiotensin system (RAS) can be blocked at different levels by agents such as renin inhibitors, ACE inhibitors and angiotensin receptor blockers (ARBs). Previous 
studies suggested that renin inhibition is more effective than the ACE inhibitors or the ARBs in blocking the function of RAS (Cordero et al. 1991; Fisher et al. 1994). Traditional RAS blockade by ACE inhibitors or by ARBs has been shown to cause a compensatory increase in renin release which might decrease the potential effects of these agents (Johnston et al. 1979; Jones et al. 2007).

Aliskiren is a direct renin inhibitor which may offer benefits in control of hypertension and cardiovascular functions over other conventional RAS blocking agents (Jensen et al. 2008). The renoprotective effects of aliskiren were demonstrated in many experimental animal models such as renal ischemia/reperfusion injury (Hammad et al. 2013), gentamicin-induced nephropathy (Bae et al. 2014). Moreover, recent evidence suggests that aliskiren improves NO bioavailability and upregulates endothelial nitric oxide synthase (eNOS) in animal model of atherosclerosis (Imanishi et al. 2008; Nussberger et al. 2008). We hypothesized that aliskiren could have a renoprotective effect against adenine-induced nephropathy. So, the present study was designed to investigate the possible protective effect of aliskiren against adenine-induced nephropathy as well as its effect on oxidative stress markers, eNOS and Nrf2 expression and apoptotic marker (caspase-3).

\section{Materials and Methods}

\section{Experimental Animals}

Forty male Sprague-Dawley rats weighing 150-200 g were individually housed in standard cages at Department of Pharmacology, Mansoura Faculty of Medicine and 
maintained on a $12 \mathrm{~h}$ light-dark cycle. Animals fed on standard diet and water adlibitum. All experiments were conducted in accordance with the NIK Guide for the Care and Use of Laboratory Animals and were approved by our local Committee for Animal Experiments.

\section{Experimental Study design}

Animals were subdivided into 4 equal groups (10 rats each)

1. Control group: normal rats received $1 \mathrm{ml}$ normal saline via oral gavage for 12 weeks.

2. Aliskiren group: normal rats received $10 \mathrm{mg} / \mathrm{kg}$ aliskiren (Rasilez tablets, Novartis Europharm limited company; aliskiren $150 \mathrm{mg}$ ) dissolved in normal saline via oral gavage for 12 weeks.

3. Adenine group: rats received high adenine diet for 4 weeks and $1 \mathrm{ml}$ normal saline via oral gavage for 12 weeks (Price et al. 2006).

4. Adenine + Aliskiren group: rats received high adenine diet for 4 weeks and aliskiren $(10 \mathrm{mg} / \mathrm{kg}$ ) via oral gavage for 12 weeks (Wood et al. 2005).

\section{High adenine diet rat model}

At the start of the experiment, the normal chow was exchanged with a special formulated diet on which the animals were maintained until kidney failure was achieved (indicated by elevation in serum creatinine above $1.5 \mathrm{mg} / \mathrm{dl}$ ). The specially formulated diet contained adenine at concentration of $0.75 \%, 2.5 \%$ protein, $1.06 \%$ calcium $\left(\mathrm{Ca}^{+2}\right)$ and $0.92 \%$ phosphorus (P) but with the addition of artificial flavours to increase palatability (bacon and sugar flavours) for 4 weeks (Price et al. 2006). 


\section{Measurement of body mass, heart rate and mean arterial blood pressure}

By the end of the experiment, rat body mass in gram was measured. Heart rate and mean arterial blood pressure were measured by indirect rat tail pressure meter (LE 5001 S.T; Department of Medical Physiology, Mansoura faculty of Medicine).

\section{Collection of blood and urine samples and harvesting kidney tissues}

By the end of experiment, rats placed in metabolic cages for collection of 24 hour urine and blood samples were obtained from the ophthalmic venous plexus using a finewalled Pasteur pipette under halothane anaesthesia. The blood samples were collected blood into 2 tubes (EDTA containing tube for measurement of $\mathrm{Hb}$ and plasma renin activity) and vacuum tube to collect serum which was stored at $-20^{\circ} \mathrm{C}$ until biochemical analysis. Also, by the end of experiment, both kidneys were collected and dissected into 2 longitudinal halves, the first one was placed into formalin $10 \%$ for histopathological study and $2^{\text {nd }}$ part was rapidly freezed and stored at liquid nitrogen $-170{ }^{\circ} \mathrm{C}$ for measurement of oxidative stress markers and PCR study.

\section{Measurement of $\mathrm{Hb}$ and serum creatinine, $\mathrm{BUN}$, electrolyte $\left(\mathrm{Na}^{+}, \mathrm{K}^{+}, \mathrm{P}\right.$ and $\left.\mathrm{Ca}^{2+}\right)$, urinary albumin excretion, plasma renin activity (PRA) and serum aldosterone and creatinine clearance}

These markers were measured by colorimetric method through specific kits according to manufacturer instructions. Kits were purchased from Diamond Diagnostics, Egypt (serum creatinine, BUN and serum electrolyte $\left(\mathrm{Na}^{+}, \mathrm{K}^{+}, \mathrm{P}, \mathrm{Ca}^{2+}\right)$ and Fortress Diagnostics Limited Unit 2C Antrim Technology Park, Antrim BT41 1QS, United Kingdom (urinary 
protein excretion). Plasma renin activity (PRA) was determined by ELISA kit (cat\# CANRA-4600) according to the manufacturer's instructions by using Segma 690 microplate reader and the results were expressed as $\mathrm{ngAngI} / \mathrm{ml} / \mathrm{h}$. Serum aldosterone level was quantified using the ELISA technique with commercially available kits (ELISA; ab136933, Abcam, USA). The reactions were read using an ELISA microplate reader (TLACOSR 496; Mabaret-Alasafra, Alexandria, Egypt) at $405 \mathrm{~nm}$. The concentration of aldosterone was measured in $\mathrm{pg} / \mathrm{ml}$. Creatinine clearance $(\mathrm{CrCl})$ was estimated from the following equations:

$$
\mathrm{CrCl}(\mathrm{ml} / \mathrm{min})=\frac{\text { Urine creatinine }(\mathrm{mg} / \mathrm{dl}) \times \text { Urine output }(\mathrm{ml} / 24 \mathrm{hrs})}{\text { Serum creatinine }(\mathrm{mg} / \mathrm{dl}) \times 1440(\mathrm{~min})}
$$

Assay of lipid peroxidations marker (MDA) and antioxidants (GSH and catalase enzyme activity) in kidney tissues

About 50 -100 mg of kidney tissues was homogenized in 1-2 $\mathrm{ml}$ ice-cold buffer (50 $\mathrm{mM}$ potassium phosphate, $\mathrm{pH}$ 7.5,1 mM EDTA) using mortar and pestle then centrifuged at $4,000 \mathrm{rpm}$ for 15 minutes at $4{ }^{\circ} \mathrm{C}$. The supernatant was kept at $-20^{\circ} \mathrm{C}$ until it was used for analysis of oxidant and antioxidants. Malondialdhyde (MDA), reduced glutathione (GSH) and catalase enzyme activity in the supernatant of kidney homogenates were measured using a colorimetric method according to the manufacturer's instructions (BioDiagnostics, Dokki, Giza, Egypt).

Assessment of eNOS and Nrf2 genes expression in kidney tissues by real time PCR RNA extraction and cDNA synthesis 
$50-100 \mathrm{mg}$ of kidney tissues was disrupted in $1 \mathrm{ml}$ of Trizol to collect total RNA according to the manufacturer's instructions (Invitrogen Corporation, Grand Island, New York, USA). Reverse transcription was done using $1 \mu \mathrm{g}$ total RNA and a cDNA kit (high-capacity cDNA archive kit). The primer sequences for the tested genes were as follow; eNOS: forward, 5= GGACCCAAGTTTCCTCGAGTAA-3=; reverse, 5=GGATCCCAAGCAGCGTCTT-3; $\quad$ probe, $\quad$ 5=FAM-CAGCAT CACCTACGATACCCTCAGTGCA-TAMRA-3; nrf2: forward: 5'GCTATTTTCCATTCCCGAGTTAC-3', reverse: 5'-ATTGCTGTCCATCTCTGTCAG3' and GAPDH forward: 5'-TATCGGACGCCTGGTTAC-3', reverse: 5'CTGTGCCGTTGAACTTGC-3'.

\section{Real-time PCR reaction}

The reaction was performed in a total volume of $50 \mu 1$ containing $25 \mu 1$ from $1 \mathrm{x}$ TaqMan ${ }^{\circledR}$ Universal PCR with $2.5 \mu$ from 20x TaqMan ${ }^{\circledR}$ Gene Expression Assay Mix and $22.5 \mu \mathrm{l}$ of cDNA diluted in RNase-free water.The cycling parameters were as follows: initial denaturation at $95^{\circ} \mathrm{C}$ for 10 minutes, followed by 40 cycles of denaturation $95^{\circ} \mathrm{C}$ for 15 seconds, annealing at $60^{\circ} \mathrm{C}$ for 1 minute, extension at $72^{\circ} \mathrm{C}$ for 1 minute. Data analysis was carried out using ABI prism 7000 by equation $2{ }^{\Delta \Delta}$ ct (Livak and Schmittgen 2001).

\section{Immunohistochemical examination of apoptotic marker (caspase-3)}

To assess the expression of caspase- 3 by immunohistochemistry, 3 - $\mu$ m-thick sections from kidneys embedded in paraffin were prepared on charged slides and deparaffinized. Kidney sections were incubated with $0.3 \%$ hydrogen peroxide in methanol for 30 min and microwave-heated in $10 \mathrm{mM}$ citrate buffer, $\mathrm{pH} 6.0$, for 10-20 min. Monoclonal 
antibodies for anti-caspase-3 (Abcam, cat\#: ab79123) were used. Indirect immunoperoxidase was performed using ImmunoPure UltraSensitive ABC Peroxidase (Thermo Scientific, catalogue number: 32052) with (DAB) as chromogen. Tonsils were used as positive control for caspase-3. In negative control, sections were stained without the addition of a primary antibody. The apoptotic index of caspase- 3 was assessed with a standard point-counting method for the percentage of labelled tubular cells (excluding necrotic tubules) in non-overlapping, randomly selected 10 high power fields of each slide (Duan et al. 2003) .

\section{Assessment of tubulointerstitial fibrosis and kidney morphology}

For evaluation of the degree of renal cortical fibrosis in kidney sections ( $3 \mu \mathrm{m}$ thick) were stained with H\&E and Masson's trichrome. Sections were examined by light microscope (Olymbus BX51) and pictures were obtained by a PC-driven digital camera (Olymbus E-620). For assessment of tubulointerstitial fibrosis, a computer software (Cell* Olymbus Soft Imaging Solution $\mathrm{GmbH}$ ) was used. Interstitial volume index was determined as mentioned before by superposing a grid containing 100 (10x10) sampling points on pictures of 10 non-overlapping fields (x200) of Masson's trichrome stained sections (the number of points overlaying interstitial space were counted and expressed as percentage of all points and large arteries and glomeruli are excluded from the quantification) (Vielhauer et al. 2004).

Also, H\&E stained sections were examined for glomerular lesions (glomerulosclerosis, segmental collapse, proliferation and mesangial expansion) and tubulointerstitial lesions 
(leukocyte infiltration, fibrosis, tubular dilatation, or atrophy). The degree of kidney damage was scored as follow 0 , normal; grade $1,<10 \%$; grade $2,10 \%-25 \%$; grade 3 , 25\%-50\%; grade 4, 50\%-75\%; and grade 5, 75\% - 100\% (Nicholas et al. 2012).

\section{Statistical analysis}

Statistical analysis was performed using SPSS version 16 (SPSS, Chicago, IL, USA). One way ANOVA test with Tukey's posthoc test were used to study the statistical significance of other parameters among all groups. P-value $<0.05$ was considered significant.

\section{Results}

Effects of aliskiren on final body weight (g), heart rate (bpm), mean $\mathrm{ABP}(\mathrm{mmHg}), \mathrm{Hb}$, serum creatinine, BUN, aldosterone and electrolytes $\left(\mathrm{Na}^{+}, \mathrm{K}^{+}, \mathrm{P}\right.$ and $\left.\mathrm{Ca}^{2+}\right)$, urinary protein excretion and PRA in normal and adenine treated rats

Table 1 shows the results of body weight, $\mathrm{HR}$, mean $\mathrm{ABP}, \mathrm{Hb}$, serum creatinine, $\mathrm{BUN}$, $\mathrm{CrCl}$, serum electrolytes $\left(\mathrm{Na}^{+}, \mathrm{K}^{+}, \mathrm{P}\right.$ and $\left.\mathrm{Ca}^{2+}\right)$, urinary protein excretion, $\mathrm{PRA}$ and serum aldosterone in different groups. Adenine group showed significant decrease in body weight, $\mathrm{HR}$ and $\mathrm{Hb}$ with significant increase showed significant increase in mean ABP compared to control and aliskiren groups $(p<0.001)$. Administration of aliskiren in adenine treated rats caused significant increase in body weight, $\mathrm{HR}$ and $\mathrm{Hb}$ with significant decrease in mean ABP compared to adenine group $(p<0.001)$.

Also, adenine group showed significant increase in serum creatinine, BUN, serum $\mathrm{Na}^{+}, \mathrm{K}^{+}$and $\mathrm{P}$, urinary protein excretion and PRA with significant decrease in serum $\mathrm{Ca}^{2+}$ and $\mathrm{CrCl}$ compared to control and aliskiren groups $(p<0.05)$. Administration of aliskiren 
in adenine treated rats caused significant decrease in serum creatinine, $\mathrm{BUN}, \mathrm{K}^{+}$and $\mathrm{P}$, urinary protein excretion and PRA with significant increase in serum $\mathrm{Ca}^{2+}$ and $\mathrm{CrCl}$ compared to adenine group $(p<0.001)$.

Effects of aliskiren on oxidative stress markers (MDA, GSH and catalase enzyme activities) in kidney tissues

Adenine group showed significant increase in MDA (marker of lipid peroxidations) with significant decrease in GSH and catalase enzyme activity compared to control group $(p<0.001)$. Administration of aliskiren caused significant decrease in MDA with significant increase in GSH and catalase compared to adenine group $(p<0.001)$ (fig.1ac).

\section{Effects of aliskiren on expression of eNOS and nrf2 genes}

Adenine group showed significant decrease in expression of eNOS and nrf2 genes by real time PCR compared to control and aliskiren groups $(p<0.001)$. Administration of aliskiren in normal rats caused significant increase in expression of both eNOS and nrf2 genes compared to control group $(p<0.001)$. Moreover, adenine + aliskiren group showed significant increase in expression of both eNOS and nrf2 genes compared to aliskiren and adenine group ( $p<0.001)$ (fig.2a-b).

\section{Effects of aliskiren on apoptosis markers (caspase-3) expression in kidney tissues}

The kidneys harvested from adenine group showed significant increase in apoptosis labelling index $(p<0.01)$ compared with control and aliskiren groups. Also, adenine + 
aliskiren group showed significant reduction in caspase-3 expression compared to adenine group $(p<0.01)$ (fig.3a). Figures 3b-d are representative samples for caspase-3 expression from different groups.

\section{Effects of aliskiren on renal interstitial fibrosis and renal morphology}

Compared to control and aliskiren groups, the kidneys obtained from adenine group showed significant increase in interstitial fibrosis index $(p<0.01)$, while kidneys obtained from adenine + aliskiren group showed significant decrease in fibrosis index compared to adenine group $(p<0.01)$ (fig.4a). Figures $4 \mathrm{~b}-\mathrm{d}$ are representative samples from different groups. The interstitial fibrosis was mostly in perivascular and intertubular areas and indicated by a positive blue color in Masson's trichrome-stained sections.

Also, histopathological damage score of glomerular and tubulointerstitial lesions showed significant increase in adenine group compared to control and aliskiren groups ( $p$ $<0.001$ ) (fig. 5a). The degree of renal damage was significantly improved in adenine + aliskiren group compared to adenine group $(p<0.001)$. Kidneys obtained from adenine group showed marked neutrophil infiltration in the cortex, irregular dilated renal tubules with dilated peritubular capillaries and inflammatory cells, glomerular expansion and collapse and rarefaction (fig.5b-d), while those obtained from aliskiren group showing mild tubular injury in the form of few apoptotic cells and regeneration in the form of irregular dilated tubules and solid tubules and mesangial proliferation (fig.5e-f).

\section{Discussion}

The main findings of the present study can be summarized as follow a) adenine caused impairment of kidney functions and morphology, electrolyte disturbances, hypertension, increase in plasma renin activity, increase in redox state and apoptosis in kidney tissues 
and downregulation of nrf2 and eNOS genes expression, b) direct inhibition of reninangiotensin system by aliskiren caused significant improvement in all studied parameters in adenine treated rats.

In the present study, adenine administration caused significant decrease in the body weight and $\mathrm{Hb}$ contents of rats which is in agreement with previous studies (Ali et al. 2014; Ali et al., 2015; Aminzadeh et al. 2013; Inam et al. 2014; Kim et al. 2013). Reduction in body weight and $\mathrm{Hb}$ in adenine group could be explained by impairment of kidney functions by adenine treatment. Also, administration of adenine caused significant elevation of mean arterial blood pressure (ABP), PRA and serum aldosterone with significant reduction in HR. In consistence with these findings, Kim et al. (2013) and Aminzadeh et al. (2013) demonstrated significant elevation in ABP in adenine treated rats and Zhao et al. (2014) showed significant elevation in serum aldosterone level in adenine-induced CRF. The significant increase in PRA and serum aldosterone suggests involvement of renin angiotensin system in elevation of $\mathrm{ABP}$ and the significant reduction in HR suggests intact baroreceptor reflex in rats with adenine -induced CRF. On the other hand, Nguy et al. (2013) demonstrated in a rat model of adenine-induced CRF, significant reduction in PRA and HR in adenine treated rats suggesting no role for renin angiotensin in adenine-induced nephropathy and impairment of baroreceptor reflex in adenine-induced CRF. This discrepancy between this study and our study might be attributed to the duration of adenine intake. In the present study, adenine was given for 4 weeks and in study done by Nugy et al. (2013), adenine was given for a long time (11 weeks). 
In the present study, aliskiren treatment in normal rats showed no significant change in body weight, $\mathrm{Hb}$ content, $\mathrm{HR}, \mathrm{ABP}, \mathrm{PRA}$ and serum aldosterone. On other hand, aliskiren (directly inhibited renin secretion) pretreatment in adenine treated rats caused significant improvement in body weight, $\mathrm{Hb}, \mathrm{HR}, \mathrm{ABP}, \mathrm{PRA}$ and serum aldosterone suggesting involvement of renin angiotensin system in adenine-induced nephropathy. In consistence with this hypothesis, Ziypak et al. (2015) demonstrated significant reduction in serum renin and angiotensin-2 (AT-2) levels in a rat model of renal I/R injury by aliskiren pretreatment. The improvement in body weight and $\mathrm{Hb}$ could be explained by improvement in kidney functions by aliskiren.

Administration of adenine, in the present study, caused significant impairment in kidney functions (indicated by significant elevation in serum creatinine and urinary protein excretion) and kidney morphology (indicated by severe tubulo-interstitial damage in the form of tubular dilation, inflammatory cell infiltration and tubulointerstitial fibrosis with glomerular sclerosis). Similar findings were reported by previous studies (Ali et al. 2014; Aminzadeh et al. 2013; Kim et al. 2013). Aminzadeh et al. (2013) reported that adenine caused significant increase in serum creatinine, tubular and glomerular kidney tissue damage. Also, Kim et al. (2013) demonstrated deteriorations in kidney and liver functions and morphology with adenine administration. Moreover, Ali et al. (2014) demonstrated that administration of adenine $(0.4 \%)$ for 4 weeks caused elevation of kidney and heart functions and morphology. In the present study, pretreatment with aliskiren caused significant improvement in kidney functions and morphology. These findings suggest the renoprotective effects of aliskiren in adenine-induced CRF rat 
model. The renoprotective effect for aliskiren was demonstrated in other rat models of renal I/R injury (Hammad et al. 2013; Wang et al. 2013; Ziypak et al. 2015) and tacrolimus-induced nephrotoxicity (Al-Harbi et al. 2015).

Electrolyte disturbances caused by adenine administration for 4 weeks in the present study included significant increase in serum $\mathrm{K}^{+}$and $\mathrm{P}$ with significant decrease in serum $\mathrm{Ca}^{2+}$ and non-significant change in serum $\mathrm{Na}^{+}$. In agreement with these findings, previous studies demonstrated electrolyte disturbances caused by adenine in the form of hyperkalemia and hypocalcemia and hyperphosphatemia (Jia et al. 2013; Kim et al. 2013, Zhao et al. 2014). Electrolytes disturbances demonstrated in adenine treated rats could be explained by impairment of tubular functions in CKD rat model which results in increase in urinary $\mathrm{Ca}^{2+}$ and decrease in urinary $\mathrm{P}$ excretion (Kim et al. 2013). Also, Ikeda et al., (2010) reported that adenine treatment for 4 weeks caused abnormal $\mathrm{Ca}^{2+}$ dynamics in the form of reduced intestinal absorption, increased incorporation into soft tissues, especially aortic tissue and enhanced urinary excretion. Also, the present study demonstrated significant improvement of hypocalcemia, hyperphosphatemia and hyperkalemia induced by adenine by aliskiren pretreatment. This might be attributed to improvement in glomerular and tubular functions by aliskiren.

Oxidative stress and apoptosis play important role in the development and progression of CKD and its sequelae such as hypertension, interstitial fibrosis, uremia and anemia (Ali et al. 2015; Inami et al. 2014; Nicholas et al. 2012). The present study demonstrated enhanced oxidative stress state in kidney tissues (evidenced by reduction in antioxidants 
(GSH and catalase enzyme) and increase in marker of lipid peroxidations (MDA). In agreement with these findings, Nicholas et al. (2012) demonstrated that administration of adenine caused significant increase in the markers of oxidative stress in plasma. Enhanced oxidative stress state in kidney tissues leads to activation of apoptosis. The present study, the expression of capase-3 (marker of apoptosis) was significantly increased in kidney tissues obtained from adenine treated rats. In consistence with this finding, Ali et al. (2015) demonstrated that adenine administration caused significant increase in caspase-3 activity in kidney tissues. Treatment with aliskiren in normal rats did not cause any significant change in the oxidative stress and apoptotic markers compared to normal rats. On the other hand, aliskiren pretreatment caused significant improvement in oxidative stress markers and caspase-3 expression in kidney tissues induced by adenine. The antioxidant action of aliskiren was demonstrated by Wang et al. (2013) and Ziypak et al. (2015) in rat model of renal I/R injury and by Al-Harbi et al. (2014) in a rat model of tacrolimus-induced nephrotoxicity.

Under physiological conditions, oxidative stress activates many endogenous antioxidant and cytoprotective proteins and enzymes that prevent or limit tissue injury and dysfunction. Nuclear factor-erythroid-2-related factor 2 (Nrf2) regulates the basal activity and coordinates induction of numerous genes that encode various antioxidant and phase 2 detoxifying enzymes and related proteins (Kobayashi et al. 2006; Wakabayashi et al. 2010). Recently, Aminzadeh et al. (2013) reported that the activity of Nrf2 transcription factor is impaired in adenine-induced CRF rat model. Also, the present study demonstrated down-regulation of the expression of nrf2 gene by real time PCR in the 
kidneys of adenine treated rats. Moreover, pretreatment with aliskiren in both adenine treated and normal rats caused up regulation of nrf2 suggesting that up regulation of nrf2 gene could be one of the potential renoprotective mechanisms of aliskiren against adenine-induced CRF. The present study demonstrated for the first time, up to the best of our knowledge, upregulation of nrf2 at the level of mRNA in kidney tissues by aliskiren.

Endothelial dysfunctions in CKD result in imbalance between the vasodilators and vasoconstrictors. Peng et al. (2013) demonstrated elevation significant decrease in serum nitric oxide (vasodilator) and elevation in serum endothelin (vasoconstrictor). Also, Ali et al (2015) demonstrated elevation in serum endothelin levels in rats treated with adenine compared to normal rats. The present study demonstrated down regulation in endothelial nitric oxide synthase (eNOS) that enhanced the production of vasodilator (NO) in kidney tissues in adenine treated group suggesting that adenine impaired the vasodilator responses of the vascular endothelium. Pretreatment with aliskiren caused significant elevation in the expression of eNOS in kidney tissues obtained from adenine treated and normal rats suggesting that up regulation of eNOS might be another potential renoprotective mechanism for aliskiren against adenine-induced CRF. In consistence with these findings, Ziypak et al. (2015) demonstrated that pretreatment with aliskiren enhanced the expression of iNOS and increased serum nitric oxide in a rat model of renal I/R injury.

Although, this is the first study that demonstrates the renoprotective effect for aliskiren against adenine induced nephropathy in rats, it has several limitations such as studying its 
effect on vascular calcifications which is one of the prominent features of adenineinduced nephropathy. We thought that the vascular dysfunctions in adenine -induced nephropathy requires intake of adenine for long time (10 -12 weeks) as demonstrated in the study done by Nugy et al. (2013). We will consider this point in further study and examine the relation between impairment of vascular dysfunctions and the duration of adenine intake.

\section{Conclusions}

Direct inhibition of renin by aliskiren protects the kidney against adenine-induced nephropathy and improved accompanied electrolyte disturbances. This might be due to suppression of PRA, redox state and apoptosis in kidney tissues and upregulation of eNOS and nrf2 genes in kidney tissues.

\section{Acknowledgments}

We acknowledged Dr Azza Elhadidy (Professor of Histology and Cell Biology, Mansoura Faculty of Medicine) for helping us in interpretation of the histopathological examination.

\section{Conflict interest}

Authors declare that there is no any conflict of interest 


\section{References}

Al-Harbi, N.O., Imam, F., Al-Harbi, M.M., Iqbal, M., Nadeem, A., Al-Shahrah, OA., et al. 2015. Treatment with aliskiren ameliorates tacrolimus-induced nephrotoxicity in rats. J Renin Angiotensin Aldosterone Syst. 16(4):1329-36

Ali, B.H., Alza'abi, M., Ramkumar, A., Al-Lawati, I., Waly, MI., Beegam, S., Nemmar, A., et al. 2014. The effect of activated charcoal on adenine-induced chronic renal failure in rats. Food Chem. Toxicol. 65: 321-328

Ali,B.H., Adham, S.A., Al Za'abi, M., Waly, M.I., Yasin,J., Nemmar, A., et al. 2015. Ameliorative Effect of Chrysin on Adenine-Induced Chronic Kidney Disease in Rats. PLoS One, 10(4): e0125285.

Aminzadeh, M.A., Nicholas, S.B., Norris, K.C., and Vaziri, N.D. 2013. Role of impaired Nrf2 activation in the pathogenesis of oxidative stress and inflammation in chronic tubulo-interstitial nephropathy Nephrol. Dial. Transplant. 28(8):2038-45

Ataka, K., Maruyama, H., Neichi, T., Miyazaki, J., and Gejyo, F. 2003. Effects of erythropoietin gene electrotransfer in rats with adenine-induced renal failure. Am. J. Nephrol. 23: 315-323

Bae, E.H., Kim, I.J., Joo, S.Y., Kim, E.Y., Choi, J.S., Kim, C.S., et al. 2014. Renoprotective effects of the direct renin inhibitor aliskiren on gentamicin-induced nephrotoxicity in rats. J Renin Angiotensin Aldosterone Syst. 15(4):348-61.

Cordero, P., Fisher, N.D., Moore, T.J., Gleason, R., Williams, G.H., and Hollenberg, N.K. 1991. Renal and endocrine responses to a renin inhibitor, enalkiren, in normal humans. Hypertension, 17 (4): 510-516. 
Duan, W.R., Garner, D.S., Williams, S.D., Funckes-Shippy, C.L., Spath, I.S., and Blomme, E.A. 2003. Comparison of immunohistochemistry for activated caspase-3 and cleaved cytokeratin 18 with the TUNEL method for quantification of apoptosis in histological sections of PC-3 subcutaneous xenografts. J. Pathol. 199: 221-228.

Fisher, N.D., Allan, D., Kifor, I., Gaboury, C.L., Williams, G.H., Moore, T.J., et al. 1994. Responses to converting enzyme and renin inhibition. Role of angiotensinII in humans. Hypertension, 23(1):44-51.

Hammad, F.T., Al-Salam, S., and Lubbad, L. 2013. Aliskiren Protect the Kidney Following Ischemia Reperfusion Injury? Physiol. Res. 62: 681-690.

Ikeda, R., Imai, Y., Maruyama, W., and Mizoguchi, K. 2010. Systemic disorders of calcium dynamics in rats with adenine-induced renal failure: Implication for chronic kidney disease-related complications. Nephrology, 15: 54-62

Imanishi, T., Tsujioka, H., Ikejima, H., Kuroi, A., Takarada, S., Kitabata, H., et al. 2008. Renin inhibitor aliskiren improves impaired nitric oxide bioavailability and protects against atherosclerotic changes. Hypertension, 52:563-572.

Inami, Y., Hamada, C., Seto, T., Hotta,Y., Aruga, S., Inuma, J., et al. 2014. Effect of AST-120 on Endothelial Dysfunction in Adenine-Induced Uremic Rats. Int. J. Nephrol. 2014:164125. doi: $10.1155 / 2014 / 164125$

Jensen, C., Herold, P., and Brunner, H.R. 2008. Aliskiren: the first renin inhibitor for clinical treatment. Nat. Rev. Drug Discov. 7:399-410.

Jia, T., Olauson, H., Lindberg, K., Amin, R., Edvardsson, K., Lindholm, B., et al. 2013. A novel model of adenine-induced tubulointerstitial nephropathy in mice. BMC Nephrology, 14:116. doi: 10.1186/1471-2369-14-116. 
Johnston, C.I., Millar, J.A., McGrath, B.P., and Matthews, P.G. 1979. Longterm effects of captopril (SQ14 225) on blood-pressure and hormone levels in essential hypertension. Lancet. 2(8141):493-6.

Jones, M.R., Sealey, J.E., and Laragh, J.H. 2007 . Effects of angiotensin receptor blockers on ambulatory plasma Renin activity in healthy, normal subjects during unrestricted sodium intake. Am. J. Hypertens. 20 (8):907-16

Kim, E.J., Oh, H-A, Choi, H J, Park, J H, Kim, D.H., and Kim NJ. 2013. Heatprocessed ginseng saponin ameliorates the adenine-induced renal failure in rats. $\mathrm{J}$ Ginseng Res. 37(1): 87-93.

Kobayashi, A., Kang, M.I., Watai, Y., Tong, K.I., Shibata, T., Uchida, K., et al. 2009. Oxidative and electrophilic stresses activate Nrf2 through inhibition of ubiquitination activity of Keap1. Mol. Cell Biol. 26: 221-229

Lavi-Moshayoff, V., Wasserman, G., Meir, T., Silver, J., and Naveh-Many, T. 2010. PTH increases FGF23 gene expression and mediates the high-FGF23 levels of experimental kidney failure: a bone parathyroid feedback loop. Am. J. Physiol. 299: F882-F889

Lerman, L.O., and Chade, A.R. 2009. Angiogenesis in the kidney: a new therapeutic target.Curr. Opin. Nephrol. Hypertens. 18(2):160-5.

Levey, A.S., Atkins, R., Coresh, J., Cohen, E.P., Collins, A.J., Eckardt, K.U., et al. 2007. Chronic kidney disease as a global public health problem: approaches and initiatives: a position statement from Kidney Disease Improving Global Outcomes. Kidney Int. $72: 247-259$

Livak, K.J., and Schmittgen, T.D. 2001. Analysis of relative gene expression data using real-time quantitative PCR and the 2(-DDC (t)). Methods, 25(4): 402-408. 
Matsui, I., Hamano, T., Mikami, S., Fujii, N, Takabatake, Y., Nagasawa, Y., et al. 2009. Fully phosphorylated fetuin-A forms a min.eral complex in the serum of rats with adenine-induced renal failure. Kidney Int. 75: 915-928

Nguy, L., Johansson, M.E., Grimberg, E., Lundgren, J., Teerlink, T., Carlström, M., et al. 2013. Rats with adenine-induced chronic renal failure develop low-renin, salt-sensitive hypertension and increased aortic stiffness. Am. J. Physiol. 304: R744-R752.

Nicholas, S.B, Yuan, J., Aminzadeh, A., Norris, K.C., Crum, A., and Vaziri, N.D. 2012. Salutary effects of a novel oxidative stress modulator on adenine-induced chronic progressive tubulointerstitial nephropathy. Am. J. Transl. Res. 4(3):257-268

Nussberger, J., Aubert, J.F., Bouzourene, K., Pellegrin, M., Hayoz, D., and Mazzolai, L.2008. Renin inhibition by aliskiren prevents atherosclerosis progression: comparison with irbesartan, atenolol, and amlodipine. Hypertension, 51:1306-1311.

Peng, M., Cai, P., Ma, H., Meng, H, Xu, Y., Zhang, X., et al. 2013. Chinese herbal medicine Shenqi Detoxification Granule inhibits fibrosis in adenine induced chronic renal failure rats. Afr. J. Tradit. Complement Altern. Med. 2;11(1):194-204.

Price, P.A, Roublick, A.M, and Williamson, M.K 2006. Artery calcification in uremic rats is increased by a low protein diet and prevented by treatment with ibandronate. Kidney Int. 70, 1577-1583.

Tamagaki, K., Yuan, Q., Ohkawa, H., Imazeki, I., Moriguchi, Y., Imai, N., et al. 2006. Severe hyperparathyroidism with bone abnormalities and metastatic calcification in rats with adenine-induced uraemia. Nephrol. Dial. Transplant. 21: 651-659 
Tamura, M., Aizawa, R., Hori, M., and Ozaki, H. 2009. Progressive renal dysfunction and macrophage infiltration in interstitial fibrosis in an adenine-induced tubulointerstitial nephritis mouse model. Histochem. Cell Biol. 13: 483-490

Tanaka, T., Doi, K., Maeda-Mamiya, R., Negishi, K., Portilla, D., Sugaya, T., et al. 2009. Urinary L-type fatty acid-binding protein can reflect renal tubulointerstitial injury. Am. J. Pathol. 174: 1203-1211

Vielhauer, V., Berning, E., Eis, V., Kretzler, M., Segerer, S., Strutz, F., et al. 2004. CCR1 blockade reduces interstitial inflammation and fibrosis in mice with glomerulosclerosis and nephrotic syndrome. Kidney Int. 66 : 2264-2278

Wakabayashi, N., Slocum, S.L, Skoko, J.J, Shin, S., and Kensler, T.W. 2010. When NRF2 talks, who's listening? Antioxid Redox. Signal. 13: 1649-1663

Wang, Z., Liu, Y., Han, Y., Guan, W., Kou, X., Fu, J., et al. 2013. Protective effects of aliskiren on ischemia-reperfusion-induced renal injury in rats. Eur. J. Pharmacol. $15 ; 718(1-3): 160-6$.

Wood, J.M, Schnell, C.R, Cumin, F., Menard, J., and Webb, R.L.2005. Aliskiren, a novel, orally effective renin inhibitor, lowers blood pressure in marmosets and spontaneously hypertensive rats. J. Hypertens. 23: 417-426

Yokozawa, T., Zheng, P.D, Oura, H, and Koizumi, F. 1986. Animal model of adenine induced chronic renal failure in rats. Nephron 44: 230-234

Zhao, Y-Y, Chen, H., Tian, T, Chen, D-Q, Bai, X., Wei F. 2014. A PharmacoMetabonomic Study on Chronic Kidney Disease and Therapeutic Effect of Ergone by UPLC-QTOF/HDMS. PLoS ONE 9(12): e115467. doi:10.1371/journal.pone. 0115467 
Ziypak, T., Halici, Z., Alkan, E., Akpinar, E., Polat, B., Adanur, S., Cadirci, E., et al. 2015. Renoprotective effect of aliskiren on renal ischemia/reperfusion injury in rats: electron microscopy and molecular study. Ren Fail. 37(2):343-54.

\section{Legend of figures}

Fig. (1): Effect of aliskiren on MDA concentration (nmol/g tissue) (a), catalase enzyme activity (U/g tissue) (b) and GSH concentration ( $\mathrm{mg} / \mathrm{g}$ tissue) (c) in kidney tissues. * significant vs control group, ${ }^{\#}$ significant vs group and ${ }^{\$}$ significant vs adenine group.

Fig. (2): Effects of aliskiren on expression of mRNA of eNOS (a) and nrf2 (b) genes by real time PCR. " significant vs control group, \# significant vs aliskiren group and \$ significant vs adenine group. GAPDH is the internal control reference gene.

Fig. (3): Effect of aliskiren on apoptosis index (a). "significant vs control group, \# significant vs aliskiren group and \$ significant vs adenine group. Photomicrographs of kidney specimens showing the expression of caspase- 3 by immunohistochemistry in control group (apoptotic index 0-1\% caspase-3) (b), adenine group (apoptotic index 25\% caspase3) (c) and in adenine + aliskiren group (apoptotic index 10\% caspase-3) (d) (Immunoperoxidase DAB X400).

Fig. (4): Effect of aliskiren on fibrosis index (a) ${ }^{*}$ significant vs control group, ${ }^{\#}$ significant vs aliskiren group and \$ significant vs adenine group. Photomicrographs of kidney specimens showing mild interstitial fibrosis mostly in perivascular and intertubular areas, indicated by a positive blue color in Masson's trichrome-stained sections. Interstitial fibrosis was $1 \%$ in normal group (b), $25 \%$ in adenine group (c) and $11 \%$ in adenine + aliskiren group (d) (Masson trichrome stain X 100)

Fig. (5): Effect aliskiren on kidney damage score (a) * significant vs control group, \# significant vs aliskiren group and $\$$ significant vs adenine group. Photomicrographs of kidney specimens obtained from adenine group showing marked neutrophil infiltration in 
the cortex (H\&E200x) (b), irregular dilated renal tubules with dilated peritubular capillaries and inflammatory cells (PAS 200x)(c), glomerular expansion and collapse and rarefaction $(H \& E \times 400)(d)$ and from adenine + aliskiren group showing mild tubular injury in the form of few apoptotic cells - regeneration in the form of irregular dilated tubules and solid tubules (H\&E x200)(e) and mesangial proliferation (H\&E x200)(f). 
Table (1): Effects of aliskiren treatment on body weight, heart rate, mean $A B P, H b$, urinary protein $(\mathrm{g} / \mathrm{l})$, serum levels of creatinine $(\mathrm{mg} / \mathrm{dl}), B U N(\mathrm{mg} / \mathrm{dl})$, aldosterone $(\mathrm{pg} / \mathrm{ml})$ and electrolytes $\left(\mathrm{Na}^{+}, \mathrm{K}^{+}, \mathrm{P}\right.$ and $\left.\mathrm{Ca}^{2+}\right)$ and PRA in normal and adenine treated rats

\begin{tabular}{|c|c|c|c|c|}
\hline & Control group & Aliskiren group & Adenine group & $\begin{array}{c}\text { Adenine }+ \\
\text { Aliskiren group }\end{array}$ \\
\hline Body weight (g) & $269.64 \pm 7.63$ & $272.15 \pm 11.28$ & $218.40 \pm 8.07^{* \#}$ & $233.20 \pm 4.26^{* \# \$}$ \\
\hline $\begin{array}{l}\text { Heart rate (HR) } \\
\text { (bpm) }\end{array}$ & $394.0 \pm 10.31$ & $387.00 \pm 15.90$ & $332.0 \pm 32.42^{* \#}$ & $384.20 \pm 14.56^{\# \$}$ \\
\hline $\begin{array}{l}\text { Mean ABP } \\
(\mathrm{mmHg})\end{array}$ & $92.72 \pm 4.22$ & $90.64 \pm 3.50$ & $143.20 \pm 6.56^{* \#}$ & $99.60 \pm 9.11^{* \# \$}$ \\
\hline $\begin{array}{l}\text { Haemoglobin } \\
\text { (g/dl) }\end{array}$ & $12.08 \pm 0.35$ & $11.95 \pm 0.76$ & $7.42 \pm 0.62^{* \#}$ & $9.33 \pm 0.87^{* \# \$}$ \\
\hline $\begin{array}{l}\text { Urinary proteins } \\
(\mathrm{g} / \mathrm{L})\end{array}$ & $0.14 \pm 0.03$ & $0.11 \pm 0.04$ & $1.42 \pm 0.26^{* \#}$ & $0.235 \pm 0.08^{* \# \$}$ \\
\hline $\begin{array}{l}\text { Serum creatinine } \\
(\mathrm{mg} / \mathrm{dl})\end{array}$ & $0.78 \pm 0.04$ & $0.65 \pm 0.03$ & $1.87 \pm 0.27^{* \#}$ & $1.06 \pm 0.07^{* \# \$}$ \\
\hline $\begin{array}{l}\text { Serum BUN } \\
(\mathrm{mg} / \mathrm{dl})\end{array}$ & $29.05 \pm 2.35$ & $27.00 \pm 4.15$ & $231.25 \pm 47.55^{* \#}$ & $109.67 \pm 11.42^{* \# \$}$ \\
\hline $\begin{array}{l}\text { Creatinine } \\
\text { clearance } \\
(\mathrm{ml} / \mathrm{min})\end{array}$ & $1.13 \pm 0.20$ & $1.03 \pm 0.14$ & $0.12 \pm 0.03^{* \#}$ & $0.6 \pm 0.03^{* \# \$}$ \\
\hline $\begin{array}{l}\text { Serum Na }{ }^{+} \\
(\mathrm{mEq} / \mathrm{L})\end{array}$ & $146.91 \pm 5.65$ & $142.39 \pm 3.44$ & $149.80 \pm 5.2$ & $148.40 \pm 5.83$ \\
\hline $\begin{array}{l}\text { Serum K } K^{+} \\
(\mathbf{m E q} / \mathbf{L})\end{array}$ & $4.18 \pm 0.61$ & $4.09 \pm 0.27$ & $6.27 \pm 0.58^{* \#}$ & $4.99 \pm 0.14^{* \# \$}$ \\
\hline Serum P (mg/dl) & $5.18 \pm 0.1$ & $5.10 \pm 0.09$ & $18.16 \pm 0.75^{* \#}$ & $11.64 \pm 0.87^{* \# \$}$ \\
\hline $\begin{array}{l}\text { Serum } \mathrm{Ca}^{2+} \\
(\mathrm{mg} / \mathrm{dl})\end{array}$ & $7.66 \pm 0.47$ & $8.03 \pm 0.43$ & $5.93 \pm 0.51^{* \#}$ & $9.19 \pm 0.71^{* \# \mathrm{~S}}$ \\
\hline $\begin{array}{l}\text { PRA (ng. AngI } \\
/ \mathrm{ml} / \mathrm{h})\end{array}$ & $0.23 \pm 0.03$ & $0.22 \pm 0.04$ & $5.52 \pm 0.48^{* \#}$ & $3.05 \pm 0.27^{* \# \$}$ \\
\hline $\begin{array}{l}\text { Serum } \\
\text { aldosterone } \\
(\mathrm{pg} / \mathrm{ml})\end{array}$ & $31.25 \pm 1.72$ & $33.19 \pm 0.92$ & $74.38 \pm 5.69^{* \#}$ & $51.05 \pm 1.26^{* \# \mathbb{S}}$ \\
\hline
\end{tabular}



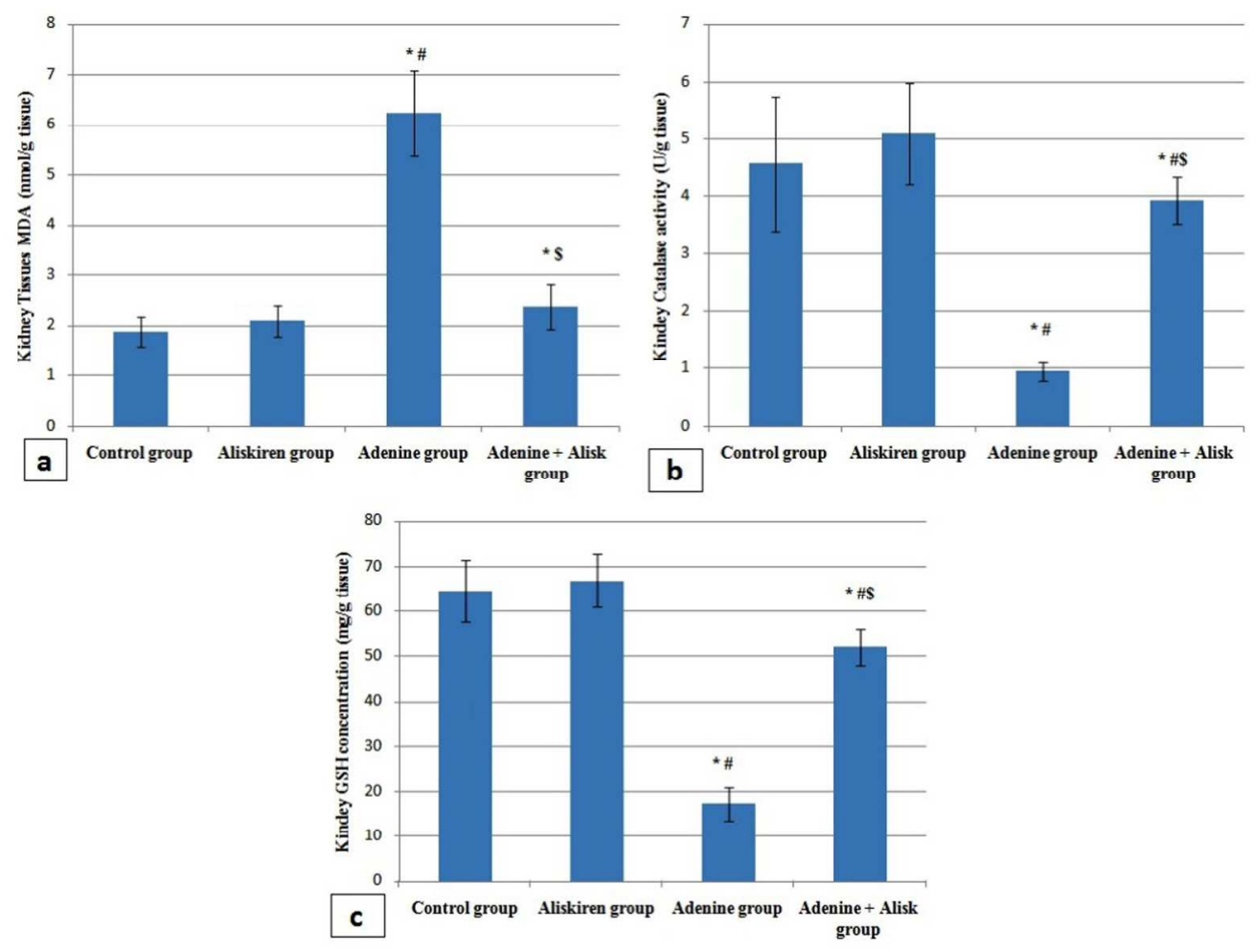

Figure 1.

$266 \times 201 \mathrm{~mm}(300 \times 300$ DPI $)$ 

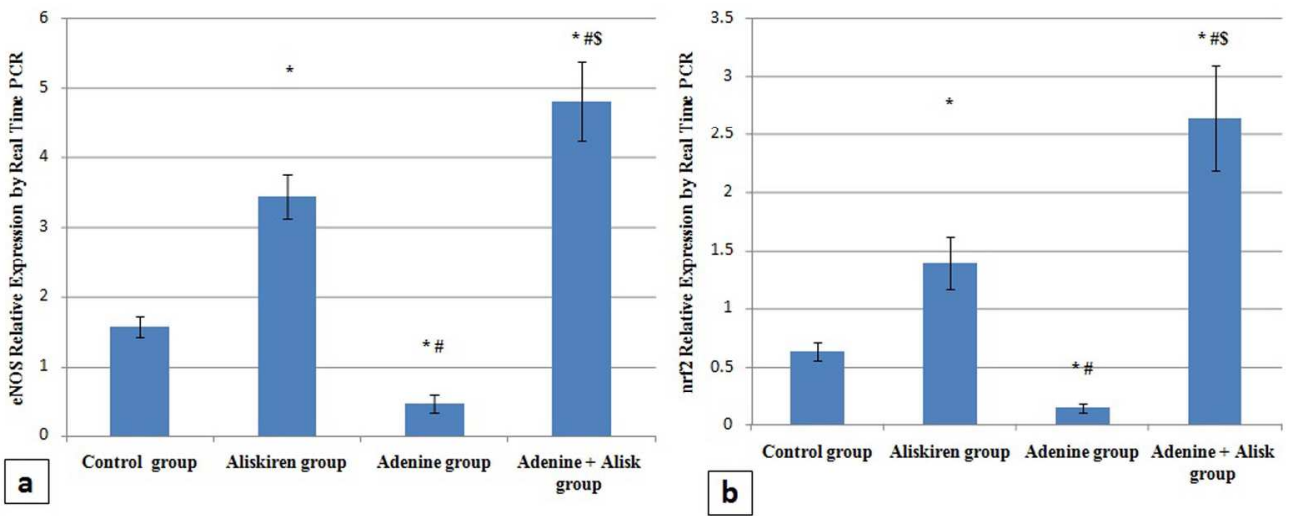

Figure 2.

$267 \times 108 \mathrm{~mm}(300 \times 300$ DPI $)$ 

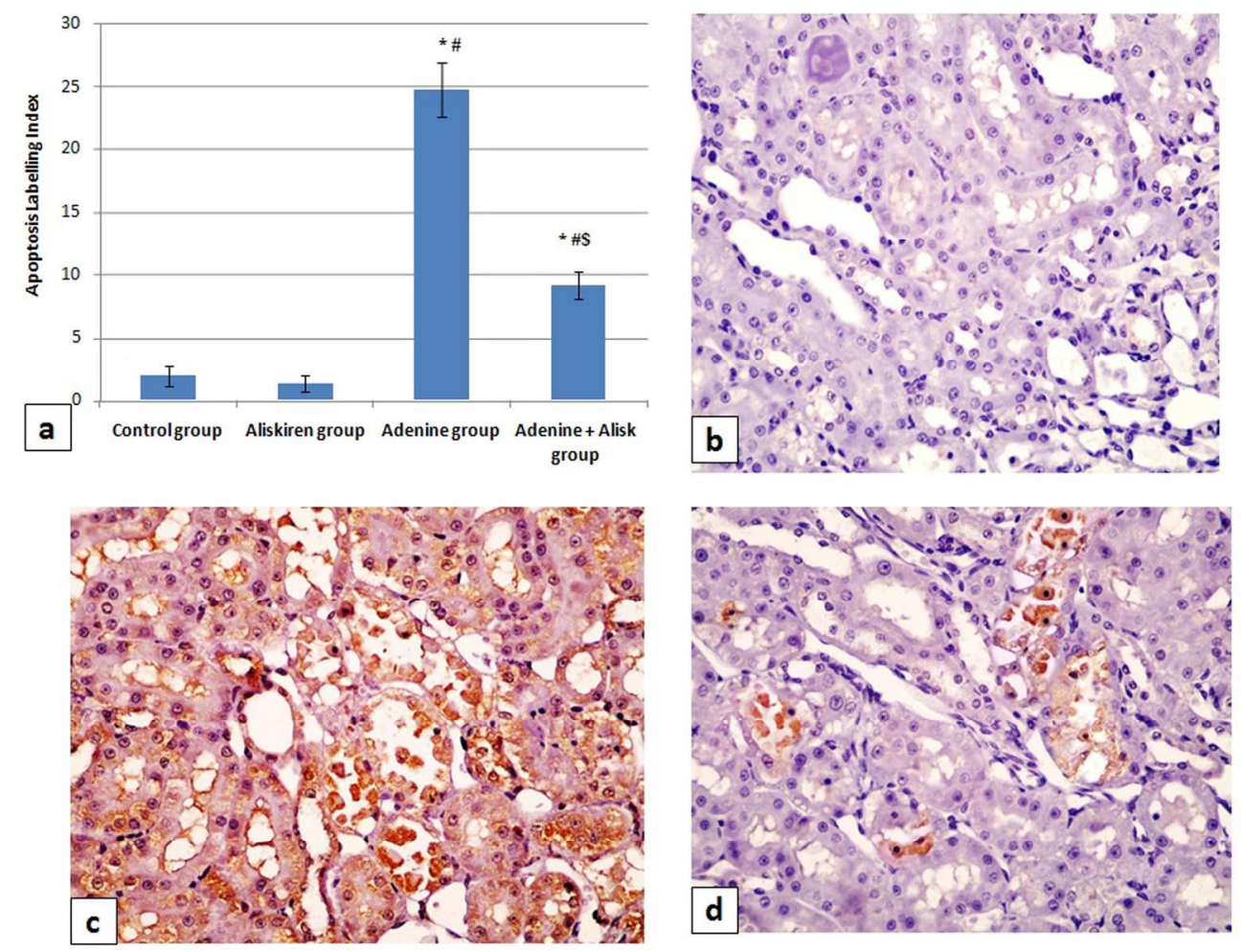

Figure 3 .

$245 \times 188 \mathrm{~mm}(300 \times 300$ DPI $)$ 

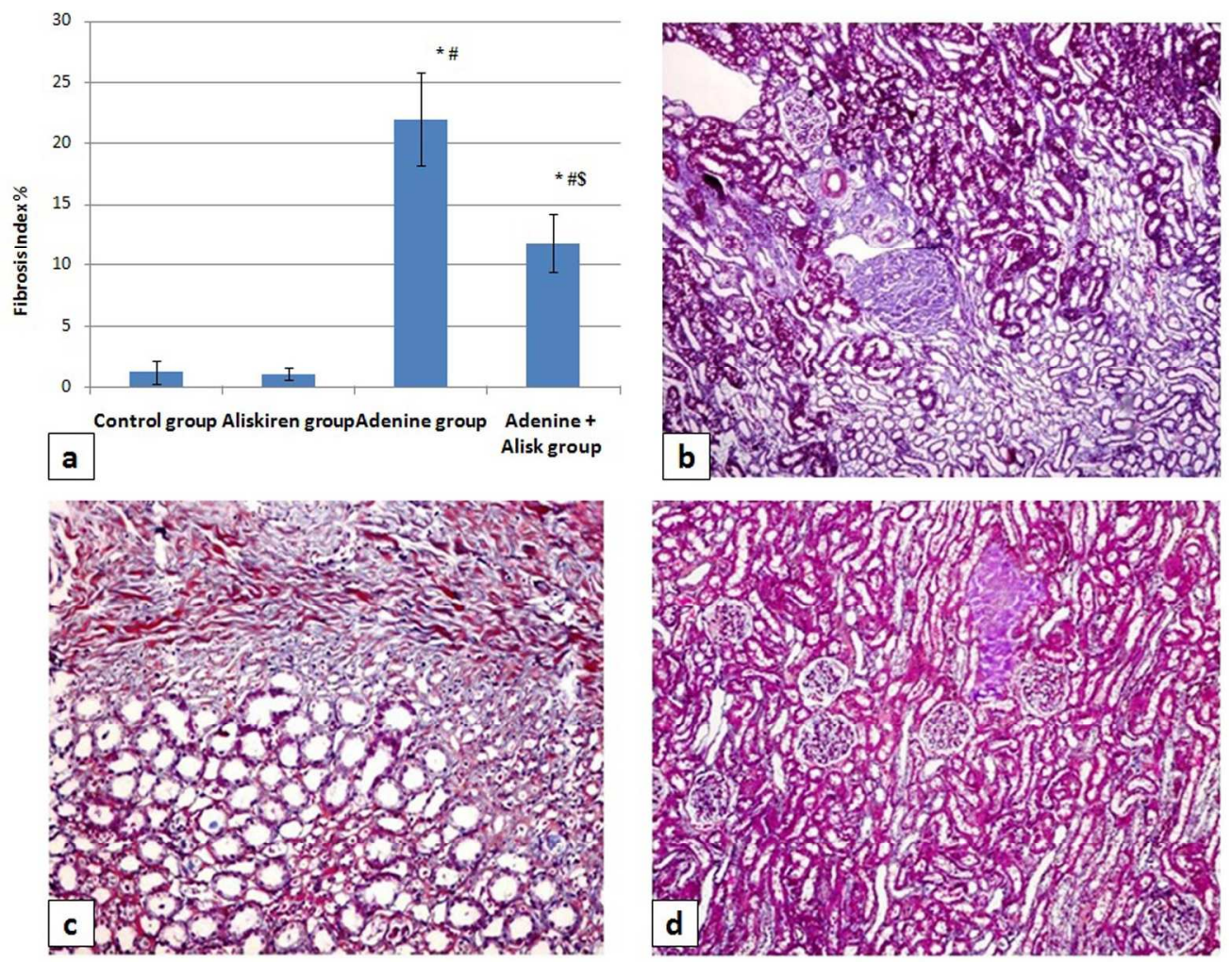

Figure 4.

$243 \times 188 \mathrm{~mm}(300 \times 300 \mathrm{DPI})$ 

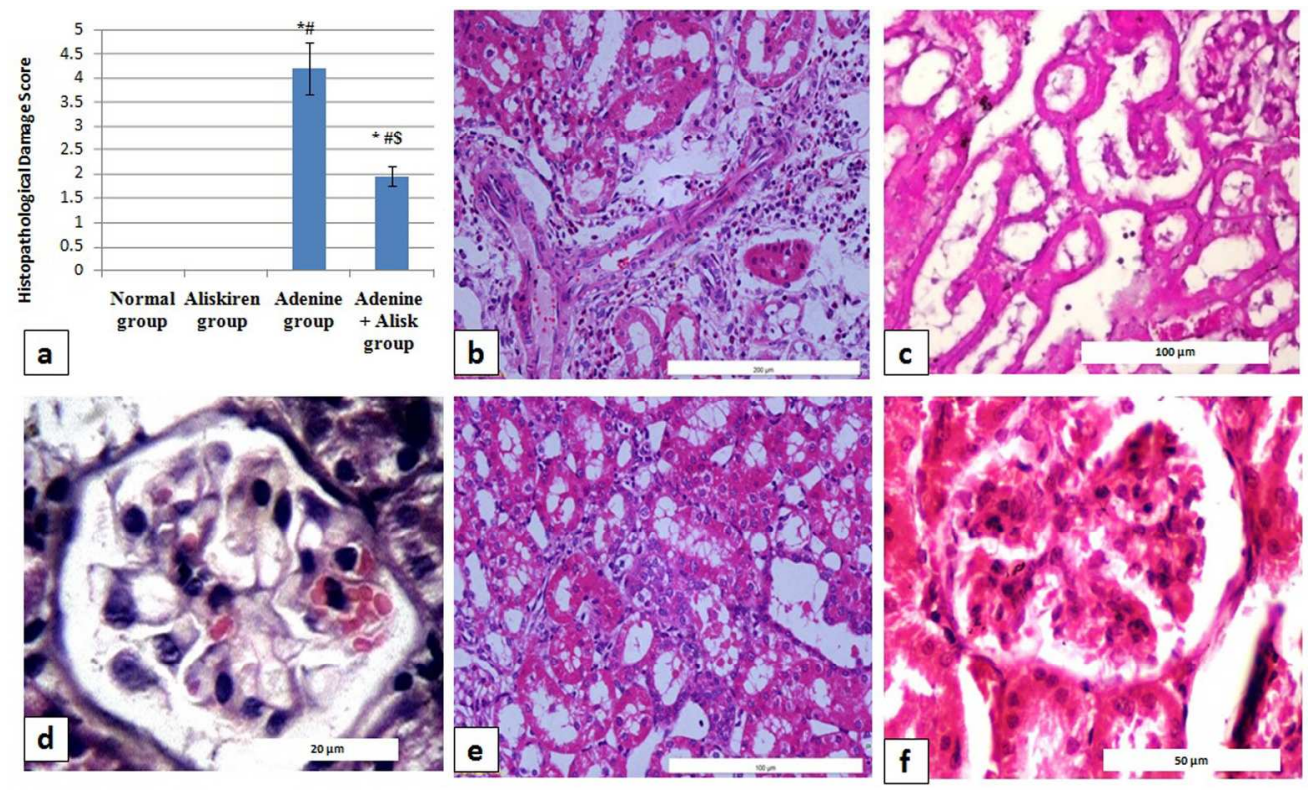

Figure 5.

$266 \times 161 \mathrm{~mm}(300 \times 300$ DPI $)$ 